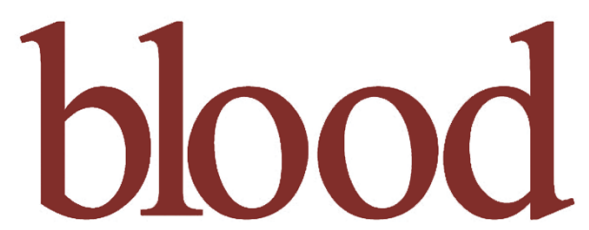

2013 122: 143-153

Prepublished online May 20, 2013;

doi:10.1182/blood-2012-11-459347

\title{
Notch1 regulates angio-supportive bone marrow-derived cells in mice: relevance to chemoresistance
}

Jeanine M. L. Roodhart, Huanhuan He, Laura G. M. Daenen, Arnaud Monvoisin, Chad L. Barber, Miranda van Amersfoort, Jennifer J. Hofmann, Freddy Radtke, Timothy F. Lane, Emile E. Voest and M. Luisa Iruela-Arispe

Updated information and services can be found at:

http://bloodjournal.hematologylibrary.org/content/122/1/143.full.html

Articles on similar topics can be found in the following Blood collections

Vascular Biology (421 articles)

Information about reproducing this article in parts or in its entirety may be found online at:

http://bloodjournal.hematologylibrary.org/site/misc/rights.xhtml\#repub_requests

Information about ordering reprints may be found online at:

http://bloodjournal.hematologylibrary.org/site/misc/rights.xhtml\#reprints

Information about subscriptions and ASH membership may be found online at: http://bloodjournal.hematologylibrary.org/site/subscriptions/index.xhtml

Blood (print ISSN 0006-4971, online ISSN 1528-0020), is published weekly by the American Society of Hematology, 2021 L St, NW, Suite 900, Washington DC 20036.

Copyright 2011 by The American Society of Hematology; all rights reserved.

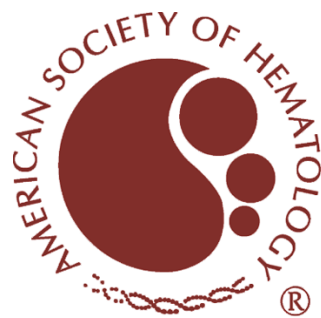




\title{
Notch1 regulates angio-supportive bone marrow-derived cells in mice: relevance to chemoresistance
}

\author{
Jeanine M. L. Roodhart, ${ }^{1}$ Huanhuan He, ${ }^{2}$ Laura G. M. Daenen, ${ }^{1}$ Arnaud Monvoisin, ${ }^{3}$ Chad L. Barber, ${ }^{4}$ \\ Miranda van Amersfoort, ${ }^{1}$ Jennifer J. Hofmann, ${ }^{4}$ Freddy Radtke, ${ }^{5}$ Timothy F. Lane,,${ }^{4,6}$ Emile E. Voest, ${ }^{1}$ \\ and M. Luisa Iruela-Arispe 3,4 \\ ${ }^{1}$ Department of Medical Oncology, University Medical Center Utrecht, Utrecht, The Netherlands; ${ }^{2}$ Department of Human Genetics, ${ }^{3}$ Department of \\ Molecular, Cell and Developmental Biology, and ${ }^{4}$ Molecular Biology Institute, UCLA, Los Angeles, CA; ${ }^{5}$ Ecole Polytechnique Federale de Lausanne, \\ Lausanne, Switzerland; and ${ }^{6}$ Department of Obstetrics and Gynecology and Biological Chemistry, UCLA, Los Angeles, CA
}

\section{Key Points}

- Exposure to chemotherapy promotes the exit of specific subpopulations of BMDCs with angio-supportive activity.

- Notch in BMDCs is required for the exit of these cells from the bone marrow and for chemotherapy-enhanced angiogenesis in tumors.
Host responses to chemotherapy can induce resistance mechanisms that facilitate tumor regrowth. To determine the contribution of bone marrow-derived cells (BMDCs), we exposed tumor-bearing mice to chemotherapeutic agents and evaluated the influx and contribution of a genetically traceable subpopulation of BMDCs (vascular endothelial-cadherin-Cre-enhanced yellow fluorescent protein [VE-Cad-Cre-EYFP]). Treatment of tumor-bearing mice with different chemotherapeutics resulted in a three- to 10-fold increase in the influx of VE-Cad-Cre-EYFP. This enhanced influx was accompanied by a significant increase in angiogenesis. Expression profile analysis revealed a progressive change in the EYFP population with loss of endothelial markers and an increase in mononuclear markers. In the tumor, 2 specific populations of VE-Cad-Cre-EYFP BMDCs were identified: $\mathrm{Gr}^{+} / \mathrm{CD} 11 \mathrm{~b}{ }^{+}$and $\mathrm{Tie}^{\text {high }} /$ platelet endothelial cell adhesion molecule ${ }^{\text {low }}$ cells, both located in perivascular areas. A common signature of the EYFP population that exits the bone marrow is an increase in Notch. Inducible inactivation of Notch in the EYFP ${ }^{+}$ BMDCs impaired homing of these BMDCs to the tumor. Importantly, Notch deletion reduced therapy-enhanced angiogenesis, and was associated with an increased antitumor effect of the chemotherapy. These findings revealed the functional significance of a specific population of supportive BMDCs in response to chemotherapeutics and uncovered a new potential strategy to enhance anticancer therapy. (Blood. 2013;122(1):143-153)

\section{Introduction}

Anticancer treatment, including chemotherapy, vascular disruptive agents, antiangiogenic agents, and even surgery, induces host responses that can reduce the efficacy of therapy. ${ }^{1-9}$ These host responses promote changes in the (tumor) microenvironment including the influx of bone marrow-derived cells (BMDCs), as well as mesenchymal, inflammatory, and vascular cells, to the tumor. These cells might partially negate the anticancer effects of treatment by providing survival signals and inducing angiogenesis. ${ }^{1-3,7,9-13}$ In particular, the increase of BMDCs after chemotherapy has been recently considered as an important cause for reduced responsiveness to chemotherapy and for enhanced angiogenesis.

Our understanding of vascular growth in tumors has evolved from the simple model of endothelial sprouting into a multifaceted process that also includes local activation and support by additional cell types. Specifically, BMDCs featuring characteristics and properties of macrophages have been found to support angiogenesis in various mouse models. ${ }^{14} \mathrm{Gr}^{+}$and $\mathrm{CD} 11 \mathrm{~b}^{+}$cells, including Tie2-expressing monocytes and tumor-associated macrophages (TAMs), can catalyze angiogenesis by producing proangiogenic factors and/or function as "vascular bridges" by guiding and connecting the filopodia tips of

Submitted November 14, 2012; accepted May 6, 2013. Prepublished online as Blood First Edition paper, May 20, 2013; DOI 10.1182/blood-2012-11-459347.

E.E.V. and M.L.I.-A. contributed equally to this study.

The online version of this article contains a data supplement. nascent vessels. ${ }^{7,12,15-19}$ Selective loss of these cells results in reduced tumor growth and impaired angiogenesis. ${ }^{11}$ However, whether these BMDCs contribute to angiogenesis by direct incorporation into the vascular wall or whether they assist in other aspects of vascular morphogenesis has been the subject of lively debate. To date, the relative contribution of BMDCs to tumor vasculature has been reported to range from $<0.1 \%$ up to $>50 \%,{ }^{20-23}$ and there is still a lack of consensus on the definition, origin, and specific function of "the endothelial progenitor cell." This lack of a defined phenotype is partially due to the fact that these cells most likely change their surface markers as they egress the bone marrow, circulate, and enter the tumor microenvironment. Most articles define endothelial progenitor cells as BMDCs expressing vascular markers, like vascular endothelialcadherin (VE-cadherin), vascular endothelial growth factor receptor 2 (VEGFR-2), CD133, and CD31, in the absence of hematopoietic markers. ${ }^{24}$ However, a significant body of evidence indicates that these cells are in fact bone marrow-derived (BMD) proangiogenic hematopoietic cells and lack true endothelial properties. ${ }^{25}$

The aims of this study were to determine the contribution of the chemotherapy-induced influx of BMD angio-supportive cells to

The publication costs of this article were defrayed in part by page charge payment. Therefore, and solely to indicate this fact, this article is hereby marked "advertisement" in accordance with 18 USC section 1734. 
chemoresistance in solid tumors, to understand their relationship to previously described populations, and to gain additional information as to the signaling pathways that regulate their function.

\section{Materials and methods}

\section{Animal models}

Studies were conducted in accordance with the Animal Research Committee guidelines established by the University of California, Los Angeles and the University Medical Center Utrecht, The Netherlands. VE-cadherin-Cre/R26R mice, VE-cadherin-Cre/EYFP mice, inducible VE-cadherin-Cre-ER ${ }^{\mathrm{T} 2} /$ enhanced yellow fluorescent protein (EYFP) mice, inducible VE-cadherin-Cre-ER ${ }^{\mathrm{T} 2}$ / R26R (CIVE) mice, and inducible VE-cadherin-Cre-ER ${ }^{\mathrm{T} 2} / \mathrm{NOTCH} / \mathrm{EYFP}$ mice were described elsewhere. ${ }^{26-31}$ See supplemental Table 1 for an overview. Six-week-old C57BL/6 mice (Charles River) were lethally irradiated $(1000 \mathrm{rad})$ and transplanted with $5 \times 10^{6}$ bone marrow cells from the different donor mice. Tamoxifen was prepared as described in Monvoisin et $\mathrm{al},{ }^{30}$ and $1 \mathrm{mg}$ was injected intraperitoneally every other day for the times indicated.

\section{Tumor models}

Mammary epithelial tumor cells from MMTV-c-neu transgenics (mixed background 129/C57BL) were isolated, characterized, and injected orthotopically $\left(10^{6}\right)$ into nude mice after transplantation with bone marrow cells from VE-cadherin constitutive, inducible, or control mice. Lewis lung carcinoma (LLC) cells were subcutaneously $\left(0.7 \times 10^{6}\right)$ injected into C57BL/6 mice 3 weeks after irradiation and transplantation with bone marrow cells from different donor mice. C26 colorectal cancer cells were subcutaneously $\left(1 \times 10^{6}\right)$ injected into BALB/c mice (Charles River). Tumor size was assessed with calipers using the formula width ${ }^{2} \times$ length $\times 0.5$. Treatment was initiated when tumors reached $100 \mathrm{~mm}^{3}$. Mice received intraperitoneally $6 \mathrm{mg} / \mathrm{kg}$ cisplatin or $40 \mathrm{mg} / \mathrm{kg}$ paclitaxel or a vehicle. Tumors were harvested 1 and 8 days after treatment. Blood was obtained by cardiac puncture, followed by perfusion with phosphate-buffered saline $/ 2 \mathrm{mM}$ EDTA $\left(37^{\circ} \mathrm{C}\right)$ for 3 to 5 minutes before harvesting part of the femur and tumor for fluorescenceactivated cell sorter (FACS) analysis. Thereafter, mice were perfused for 3 minutes with $1 \%$ paraformaldehyde $/ 2 \mathrm{mM}$ EDTA $\left(37^{\circ} \mathrm{C}\right)$ and organs and tumors were fixed in $4 \%$ paraformaldehyde.

\section{Flow cytometry analysis}

Single-cell suspensions were minced, incubated at $37^{\circ} \mathrm{C}$ for 15 minutes in collagenase $(1 \mathrm{mg} / \mathrm{mL}) /$ Dnase $(0.4 \mathrm{mg} / \mathrm{mL})$, and filtered with 100 - and $40-\mu \mathrm{m}$ filters (BD Biosciences). Bone marrow cells were either flushed from the femur or isolated from the blood or from the tumors. Cells were analyzed on a FACS LSR II with monoclonal antibodies or appropriate isotype controls as indicated in the supplemental Methods on the Blood website. Cells were sorted on a FACSAria using the Ag-presenting cell-conjugated platelet endothelial cell adhesion molecule (PECAM), EYFP, and 7-aminoactinomycin D Cells were gated based on size, viability, PECAM, and/or EYFP expression. FACS analysis on embryonic tissue was performed as previously described in Zovein et al. ${ }^{28}$

\section{Immunohistochemistry}

Vibratome sections $(300 \mu \mathrm{m})$ were incubated with 1:400 PECAM-1 rat antimouse antibody (BD Pharmingen); smooth-muscle actin anti-mouse (Sigma) and 1:200 Cy3 or Cy5 secondary antibody (Jackson ImmunoResearch); TO-PRO-3 (Invitrogen); or DAPI (4,6 diamidino-2-phenylindole) (Sigma). Confocal laser scanning microscopy evaluation was performed. Immunohistochemistry on CD31 and $\beta$-galactosidase ( $\beta$-gal) staining were performed as described in Alva et $\mathrm{al}^{29}$ and in supplemental Methods.

\section{Real-time reverse transcription-polymerase chain reaction (RT-PCR)}

Total RNA was extracted from FACS cells using TRIzol (Invitrogen). Complementary DNA was generated by reversed transcription in $20 \mu \mathrm{L}$ reaction mixture at $50^{\circ} \mathrm{C}$ for 1 hour. Half of that volume was mixed with SYBR Green 1 Buffer (QIAGEN). Complementary DNA was amplified by RT-PCR using specific primers. Emission of SYBR Green 1 incorporation was quantified using the threshold cycle value. Results presented are from 4 independent experiments, normalized to endogenous Hprt. Primers are shown in the supplemental Material.

\section{Results}

\section{Contribution of the different VE-cadherin-expressing cells to the tumor vasculature of unperturbed tumors}

We used several transgenic mouse models to genetically trace BMDVE-cadherin-expressing cells. First we used the constitutive VEcadherin-Cre/R26R model. In these mice, the endothelium and a large part of the hematopoietic compartment is $\beta$-gal-positive, as embryonic VE-cadherin-expressing cells give rise to both endothelial and hematopoietic progeny ${ }^{28-30}$ (Figure 1Aa). In $c$-neu, transformed mammary epithelial tumor $\beta$-gal-positive cells were found both lining and associated with blood vessels (Figure $1 \mathrm{Ab}$ ). Using VE-cadherinCre/EYFP mice, FACS analysis showed that $60 \%$ of all cells in the tumor were EYFP-positive (Figure 1B). To investigate the contribution of specifically BMD-VE-cadherin-expressing cells, we transplanted the bone marrow of VE-cadherin-Cre/R26R mice into lethally irradiated wild-type C57BL/6 mice. In the bone marrow of transplanted mice, again, $50 \%$ of the cells expressed $\beta$-gal, mostly coexpressed with CD45 (>90\%) (Figure 1Ac and supplemental Figure 1A). Tumors showed a clear influx of $\beta$-gal-positive cells, mainly $\mathrm{CD} 45^{+}$; only a very small subset of the $\beta$-gal-positive cells was actually part of the endothelium (Figure 1Ad). CD31 costaining of these sections clearly demonstrates that the recombination mainly occurs in the cells surrounding the vessels and only $0.02 \%$ of all vessel lining cells expressed $\beta$-gal (Figure 1C-E). FACS analysis showed a contribution of $50 \%$ of $\mathrm{EYFP}^{+}$cells in the tumor (Figure 1B), although we did not discriminate between circulating and tumor-resident inflammatory cells.

To bypass the ability of embryonic VE-cadherin-expressing cells to give rise to the broad cohort of hematopoietic progeny, we next used tamoxifen-inducible CIVE mice. After tamoxifen induction, a specific and widespread recombination can be found in the endothelium with very limited expression in the hematopoietic lineage. ${ }^{28-30}$ Using this strategy, we were able to identify a relative minor subpopulation $(0.3 \% \pm 0.1 \%)$ that was positive for $\beta$-gal (supplemental Figure 1B). As predicted, many of these cells were found lining blood vessels by virtue of VE-cadherin expression (endothelial cells), but others (exclusively in the bone marrow) were nonvessel-associated cells (Figure 1Ae and supplemental Figure 1C-D). In subcutaneously implanted tumors, recombined VE-cadherin-expressing cells were found lining the vasculature ${ }^{32}$ and a very small population of nonvascular cells (Figure 1Af). FACS analysis showed that the contribution of the VE-cadherin-Cre-expressing population, as per recombination of the reporter $\mathrm{EYFP}^{+}$, was remarkably reduced to, on average, $0.5 \%$ compared with the constitutive model (Figure 1B).

To distinguish between BMD-adult-VE-cadherin-expressing cells and peripheral-VE-cadherin-expressing cells, we next performed 2 different transplantation experiments. First we transplanted the bone marrow of CIVE mice into lethally irradiated wild-type C57BL/6 
A A CONSTITUTIVE MODEL
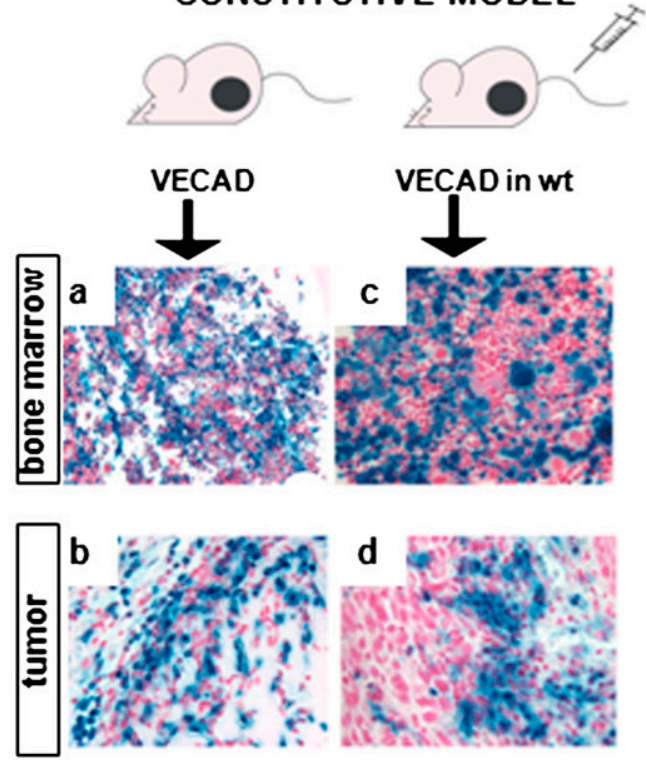

B

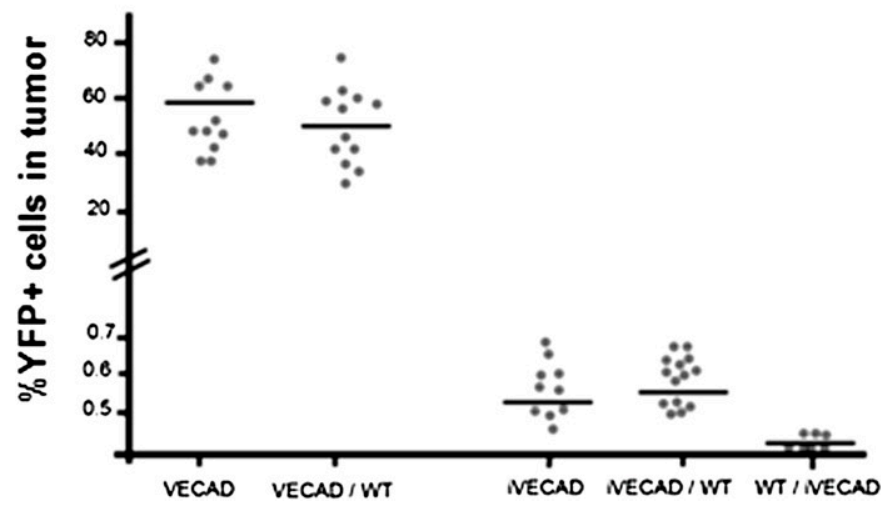

INDUCIBLE MODEL
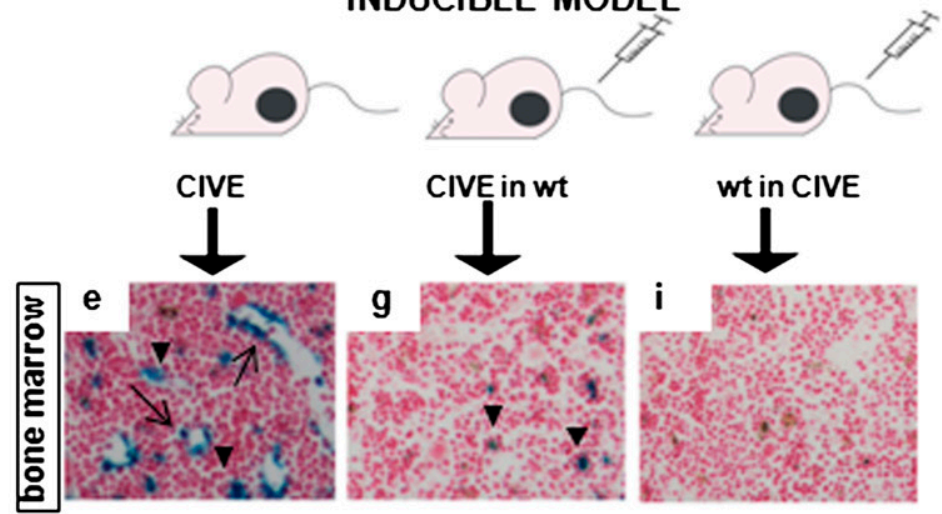

CIVE in wt

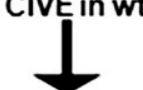
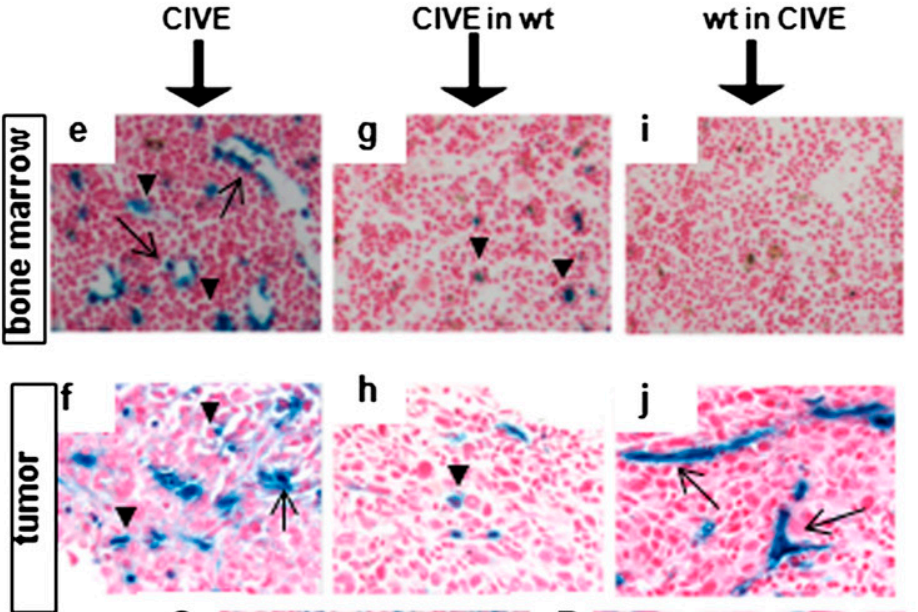

$\mathbf{h}$
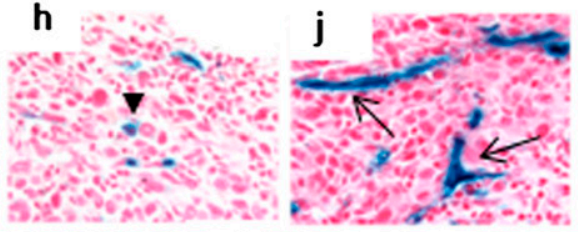

C $\beta$-gal

D $\beta$-gäl

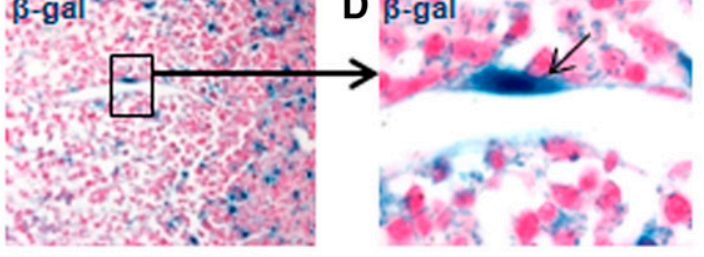

E
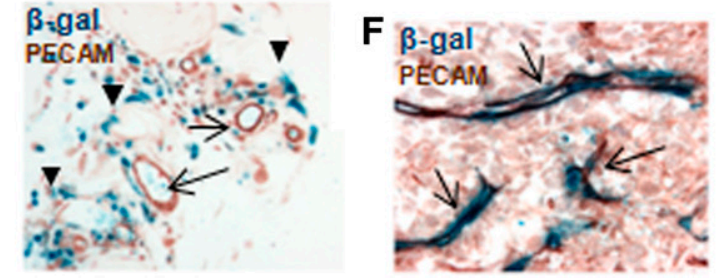

Figure 1. Contribution of the different VE-cadherin-expressing cells to the tumor vasculature of unperturbed tumors. (A) Immunohistochemical analysis of $\beta$-gal expression in bone marrow sections and sections of subcutaneous growing $c$-neu transformed mammary epithelial tumors in 5 different mouse models is shown: (Aa-b) constitutive VE-cadherin-Cre/R26R mice (VECAD), (Ac-d) bone marrow transplantation of constitutive VECAD mice in lethally irradiated wild-type (WT) C57BL/6, (Ae-f) inducible CIVE mice, (Ag-h) bone marrow transplantation of CIVE mice in lethally irradiated WT C57BL/6 mice, and (Ai-j) bone marrow transplantation of WT C57BL/6 mice into lethally irradiated CIVE mice. (B) The fluorescent versions of the above models with EYFP instead of lacZ expression were used for FACS analysis of subcutaneous growing $c$-neu transformed mammary epithelial tumors. The graph depicts the percentage of EYFP ${ }^{+}$cells in the tumors. (C-F) Shown is the immunohistochemical analysis of $\beta$-gal (and CD31 expression for $[E]$ and $[F]$ ) in the tumors of the constitutive VE-cadherin transplantation into (C-E) WT C57BL/6 mice and (F) the WT C57BL/6 transplantation into CIVE mice. All images were $20 \times$ except for $(D)(63 \times)$ and $(F)(40 \times)$.

mice. We found $0.3 \% \beta$-gal-expressing cells in the bone marrow (Figure 1Ag and supplemental Figure 1B). Tumors in these mice showed a limited influx of mainly nonvessel-associated positive cells (Figure 1Ah). In total, the influx of $\mathrm{EYFP}^{+}$cells was similar to the previous, nontransplanted CIVE model $(0.5 \%)$. However, most cells were in the nonvessel-associated compartment (Figure 1B and 1Ah). Next we transplanted bone marrow from wild-type BL/6 mice into lethally irradiated CIVE mice. As expected, bone marrow from these mice contained no $\beta$-gal-expressing cells (Figure 1Ai). When we analyzed tumors growing in these mice, the endothelium in tumor vessels was clearly $\beta$-gal-positive and no nonvessel-associated $\beta$-gal-positive cells were detected (Figure 1Aj). CD31 immunohistochemistry of previously X-gal-stained sections demonstrated that the recombination occurred in the tumor endothelium (Figure 1F). In total, $0.1 \%$ of all cells in the tumor were found to be positive in this model (Figure 1B).

Taken together, in unperturbed tumors the vast majority of the tumor endothelium is derived from adult, non-BMD-VEcadherin-expressing cells. However, a very small population of
BMD-VE-cadherin-expressing cells was found to incorporate the vascular wall of tumors at a proportion of $0.02 \%$; this was not found in normal tissues.

\section{Chemotherapy-enhanced angiogenesis is associated with an influx of BMD-VE-cadherin-expressing cells}

We next questioned whether challenging the host with maximum tolerated dose chemotherapy would affect the influx of VE-cadherin BMDCs in the tumor. We transplanted the bone marrow from tamoxifen-inducible VE-cadherin-Cre-ER ${ }^{\mathrm{T} 2} / \mathrm{EYFP}$ (CIVE/EYFP) mice into wild-type, lethally irradiated C57BL/6 mice. These animals were subsequently treated with tamoxifen to reveal the VE-cadherin-expressing population, injected with tumor cells, and subjected to chemotherapy (Figure 2A).

We first accessed the percentage of endothelial cells after different types of chemotherapy in 2 different mouse tumor models. C57BL/6 mice bearing LLC tumors and BALB/c mice bearing C26 tumors were treated with either cisplatin, paclitaxel, or a vehicle 
A

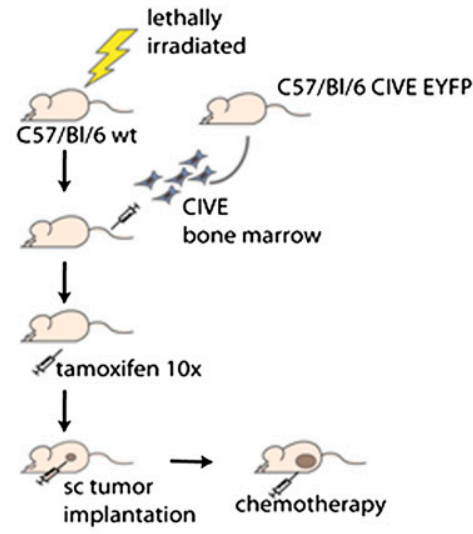

C

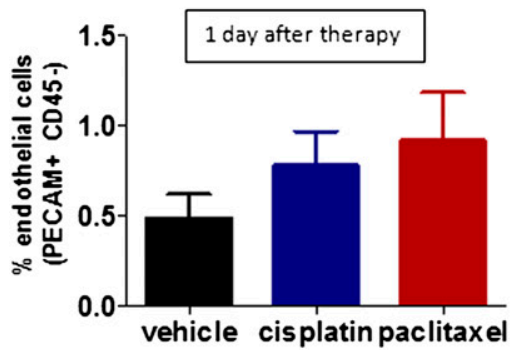

E
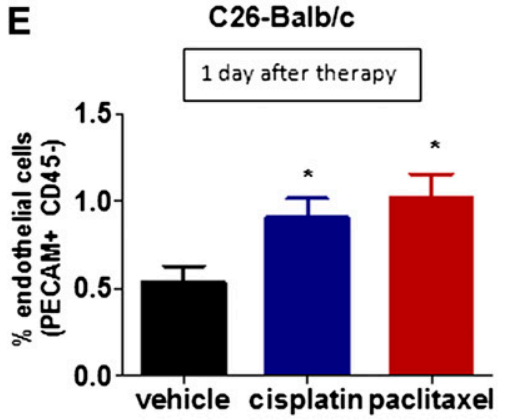

G

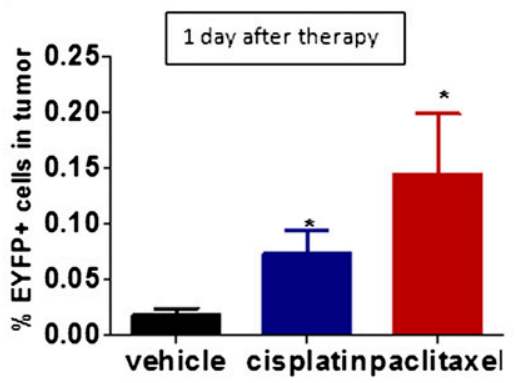

B

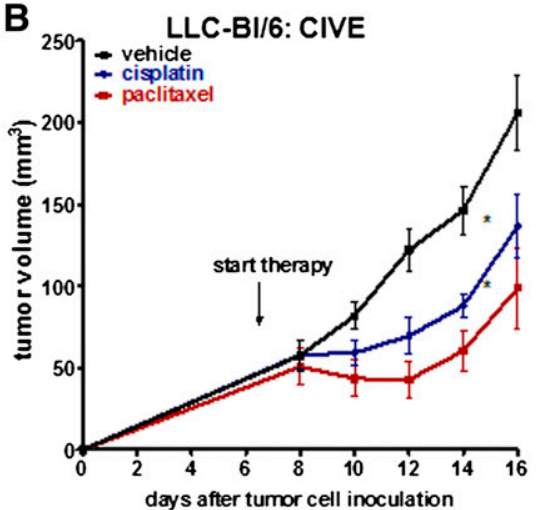

Figure 2. Chemotherapy-enhanced angiogenesis is associated with an influx of BMDCs. (A) A schematic overview of the mouse model is shown. sc, subcutaneous. (B) The graph shows the tumor growth of LLC cells in C57BL/6 mice either untreated or treated with cisplatin or with paclitaxel. (C-D) The graphs show the percentage of $\mathrm{PECAM}^{+} / \mathrm{CD} 45^{-}$cells of the total cells in subcutaneous growing LLC cells in BL/6 mice transplanted with CIVE bone marrow, (C) 1 day or (D) 8 days after the start of treatment. (E-F) The graphs show the percentage of endothelial cells in subcutaneous growing $\mathrm{C} 26$ cells in BALB/c mice $(\mathrm{E}) 1$ day or $(\mathrm{F}) 8$ days after the start of treatment. $(\mathrm{G}-\mathrm{H})$ The graphs show the percentage of EYFP ${ }^{+}$cells in LLC tumors in $\mathrm{BL} / 6$ mice transplanted with CIVE bone marrow $(\mathrm{G}) 1$ or $(\mathrm{H}) 8$ days after treatment. ${ }^{\star} P<.05 ;{ }^{\star \star} P<.01$; ${ }^{\star \star \star} P<.001$ compared with the vehicle control.
D

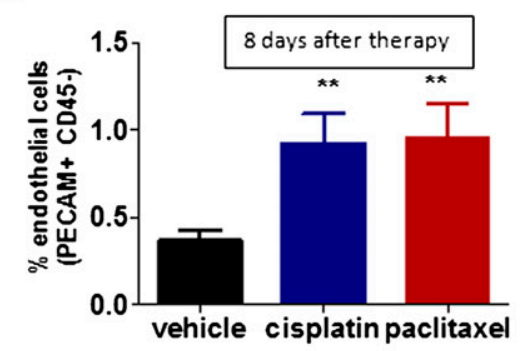

$\mathbf{F}$

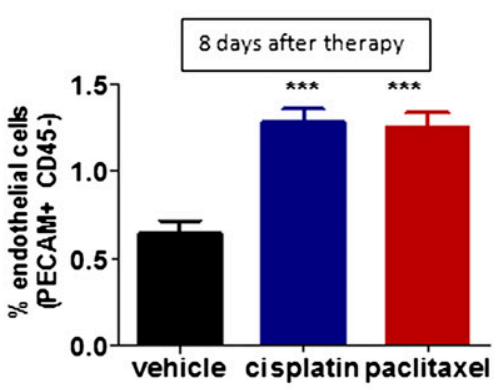

H

\section{LLC-BI/6: CIVE}

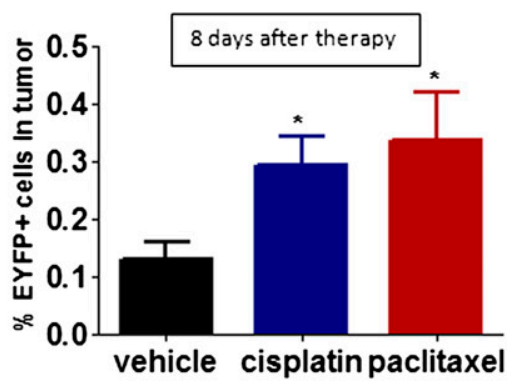

(Figure 2B and supplemental Figure 2A). In both models, a significant increase in endothelial cells in the tumor was noted after chemotherapy (Figure 2C-F), despite an initial decrease in tumor growth (Figure 2B). Confocal microscopy confirmed the presence of more vascular structures 8 days after chemotherapy (supplemental Figure 2B). Notably, C26 cells are intrinsically resistant to paclitaxel (supplemental Figure 2A).

This burst in angiogenesis was temporally correlated with a significant increase in the influx of $\mathrm{EYFP}^{+}$BMDCs in the tumor after treatment with chemotherapy (Figure 2G-H and supplemental Figure 2C). A slight increase in $\mathrm{EYFP}^{+}$cells in the circulation was detected 1 day after chemotherapy (supplemental Figure 2D-E).
The influx of $\mathrm{EYFP}^{+}$cells was specific for tumor tissue and, as in control organs like the lung, liver, and spleen, hardly any $\mathrm{EYFP}^{+}$ cells were detected and there were no differences between the treated and untreated mice (supplemental Figure 2F). In summary, systemic treatment with chemotherapy strongly increased the influx of VE-cadherin-expressing BMDCs in tumors.

\section{Specific tumor influx of 2 subpopulations of VE-cadherin-expressing BMDCs}

Confocal microscopy revealed that $\mathrm{EYFP}^{+}$cells in the tumor were found in close association with tumor vessels, whereas in areas 
Figure 3. Influx of 2 subpopulations of VE-cadherin BMDCs. (A) Representative confocal pictures show $\mathrm{EYFP}^{+}$cells in the LLC tumors (blue: TO-PRO, red: PECAM, green: EYFP). (B) Shown are adult bone marrow cells expressing VE-cadherin from 2 distinct populations: an endotheliallike population expressing PECAM and VE-cadherin and a monocytic population expressing Gr1 and CD11b. (C) Cytospins of FACS sorted BMD-EYFP ${ }^{+}$cells stained for Gr1, PECAM, and VE-cadherin are shown. (D-E) The graphs show the percentage of (D) $\mathrm{EYFP}^{+} / \mathrm{PECAM}^{+}$or (E) $\mathrm{EYFP}^{+} /$ $\mathrm{PECAM}^{+} / \mathrm{CD}^{-} 5^{-}$cells in subcutaneous growing LLC cells in BL/6 mice transplanted with CIVE bone marrow 8 days after the start of treatment. (F-G) The graphs show the percentage of (F) EYFP ${ }^{+} / \mathrm{Gr}^{+} / \mathrm{CD} 11 \mathrm{~b}^{+}$cells or $(\mathrm{G}) \mathrm{Gr}^{+} / \mathrm{CD} 11 \mathrm{~b}^{+}$cells in subcutaneous growing LLC cells in BL/6 mice transplanted with CIVE bone morrow 1 day after the start of treatment. ${ }^{*} P<.05$ compared with the vehicle control. *, single green EYFP cells; arrowheads, double-positive cells (EYFP ${ }^{+}$ $\mathrm{PECAM}^{+}$). All images were obtained at $20 \times$ except for the zoom images; scale bar sizes are indicated.
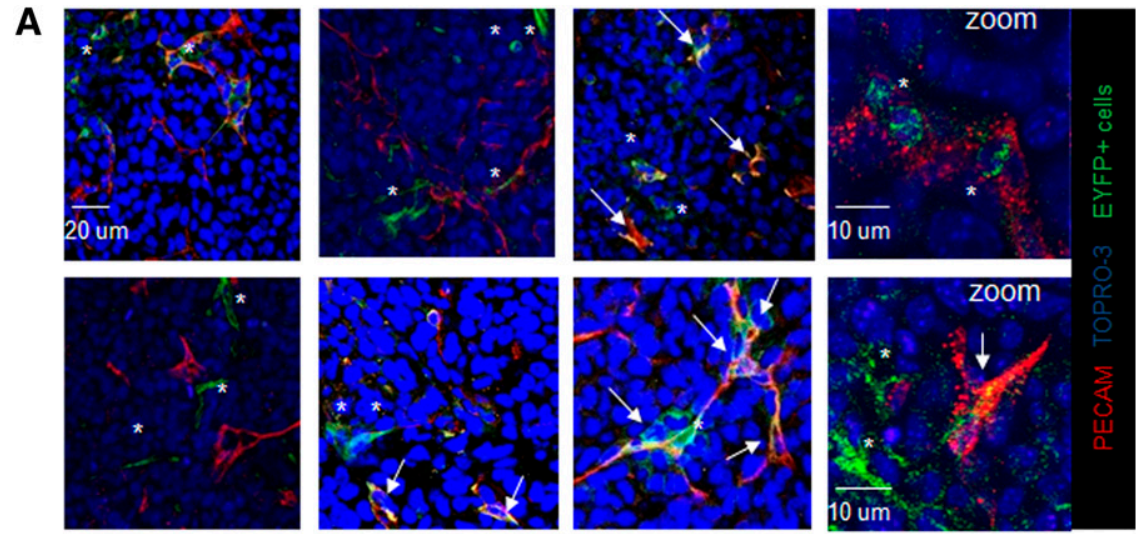

B
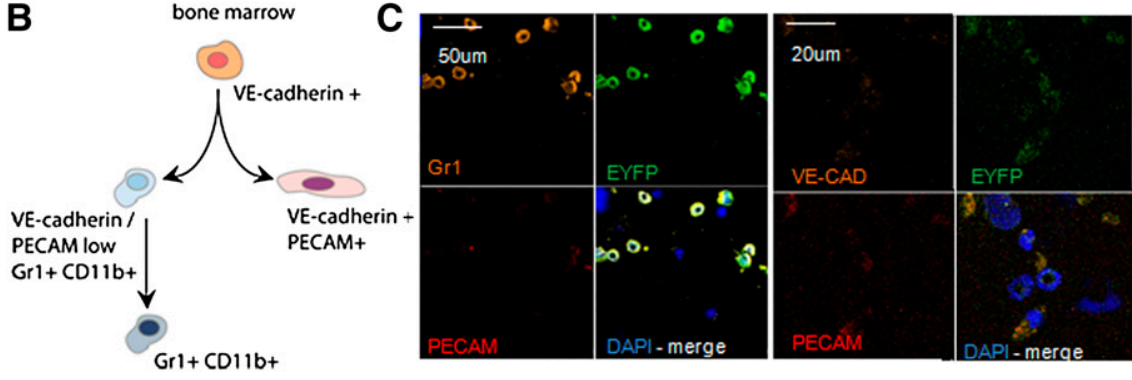

D

LLC-BI/6: CIVE

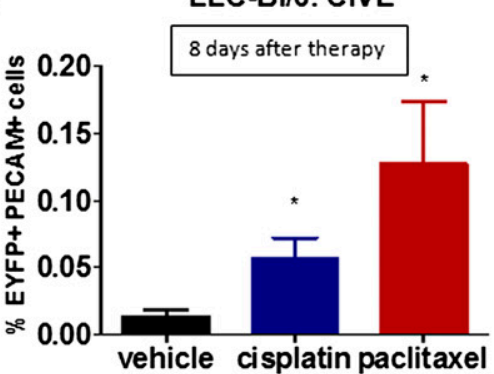

$\mathbf{E}$

LLC-BI/6: CIVE

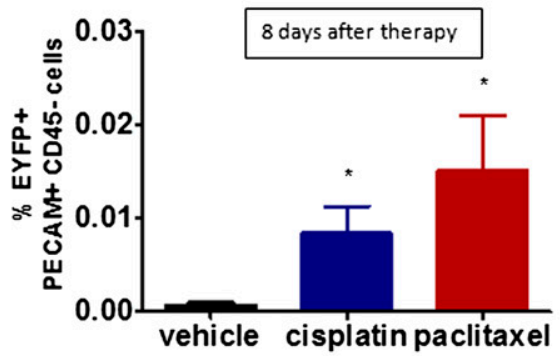

$\mathbf{F}$

LLC-BI/6: CIVE

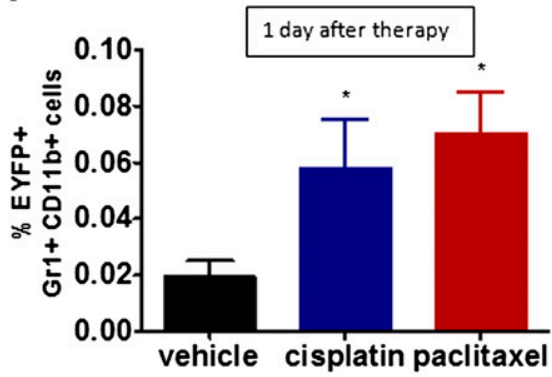

$\mathbf{G}$

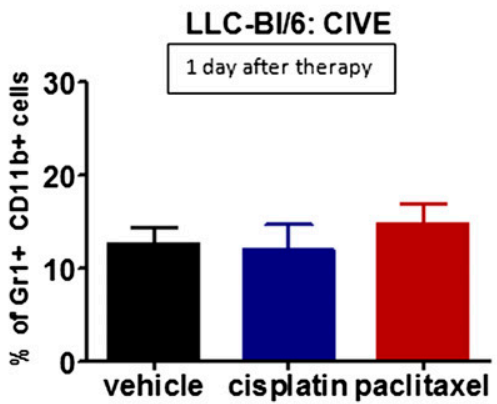

without vessels hardly any $\mathrm{EYFP}^{+}$cells were noted (Figure $3 \mathrm{~A}$ and supplemental Figure 3A). After chemotherapy, more EYFP cells were identified per vascular structure than in the untreated tumors (supplemental Figure 3B). Although the $\mathrm{EYFP}^{+}$cells clustered around the vessels, only a few $\mathrm{EYFP}^{+} / \mathrm{PECAM}^{\text {low }}$ cells were seen (Figure 3A). In order to further characterize the influx of $\mathrm{EYFP}^{+}$cells, we analyzed the phenotype of the EYFP ${ }^{+}$cells in the bone marrow of these transplanted mice (supplemental Table 2). As noted before, the $\mathrm{EYFP}^{+}$population constituted only $0.3 \%$ of all bone marrow cells. Eighty percent of the $\mathrm{EYFP}^{+}$cells expressed the hematopoietic marker CD45 and were divided into an endotheliallike population coexpressing VE-cadherin, PECAM, and VEGFR-2 and a population expressing monocyte/macrophage markers CD11b and Gr1 (Figure 3B-C). After cisplatin or paclitaxel chemotherapy, an increase in both $\mathrm{EYFP}^{+} / \mathrm{PECAM}^{\text {low }}$ cells and in $\mathrm{EYFP}^{+} / \mathrm{Gr}^{+} / \mathrm{CD} 11 \mathrm{~b}^{+}$cells was seen in the tumor (Figure 3D,F), and both cell types are known for their proangiogenic properties. $7,10,11,15-19,23,24,32-34$

In the untreated tumors, on average $0.45 \%$ of all PECAM $^{\text {low }}$ cells were EYFP-positive. However, the majority of these cells coexpressed CD45 and therefore belongs to the hematopoietic lineage. When focusing on only the PECAM ${ }^{\text {low }} / \mathrm{CD} 45^{-}$cells, only $0.002 \%$ of these cells were yellow fluorescent protein (YFP)-positive. Remarkably, after treatment with chemotherapy this percentage 
increased to $0.1 \%$ upon cisplatin, and $0.16 \%$ upon paclitaxel, exposure (Figure 3D-E). This relative increase in $\mathrm{EFYP}^{+} / \mathrm{PECAM}^{+}$ cells exceeded the increase of the total $\mathrm{EYFP}^{+}$cells (2.2- and 2.6fold, respectively), suggesting a specific influx of $\mathrm{PECAM}^{\text {low }} /$ $\mathrm{CD} 45^{-}$/EYFP cells. The specificity was further supported by our findings in the constitutive VE-cadherin-Cre/EYFP model. Using the bone marrow from these mice resulted in much higher levels of EYFP cells in the tumor when compared with the inducible model (supplemental Figure 3C). However, no overall increase in $\mathrm{EYFP}^{+}$ cells was seen after chemotherapy (supplemental Figure 3C), showing that there is no general increased influx of BMDCs. We did find a specific increase in EYFP/PECAM ${ }^{\text {low }}$ cells with borderline significance $(P=.05)$ after chemotherapy (supplemental Figure 3D).

In addition to the influx of PECAM ${ }^{\text {low }} / \mathrm{EYFP}$ cells, 1 day after chemotherapy a significant increase of EYFP/Gr $1^{+} / \mathrm{CD} 11 \mathrm{~b}^{+}$cells was noted (Figure 3F). Interestingly, there was no increase in the overall $\mathrm{Gr}^{+} / \mathrm{CD} 11 \mathrm{~b}^{+}$population (Figure $3 \mathrm{G}$ ). This shows a specific influx of the EYFP/Gr1 ${ }^{+} / \mathrm{CD} 11 \mathrm{~b}^{+}$cells and suggests that these cells actually might be different from their counterparts that did not express VE-cadherin. Notably, after 8 days, the EYFP/Gr1 ${ }^{+} / \mathrm{CD} 11 \mathrm{~b}^{+}$levels were similar in all groups, with an average contribution of $0.01 \%$ (standard deviation 0.07). Because the total number of EYFP cells in the tumor increased later on, we predicted that this population will lose these specific markers over time. In addition to directly enhancing angiogenesis, $\mathrm{Gr}^{+} / \mathrm{CD} 1 \mathrm{~b}^{+}$cells have been found to promote maturation of vessels via better pericyte coverage. ${ }^{35} \mathrm{We}$ found a significant increase in pericyte coverage of tumor vessels 8 days after chemotherapy (supplemental Figure 4A) compared with the untreated tumors, with only a small part of the smooth-muscle actin ${ }^{+}$cells being EYFP-positive (supplemental Figure 4B). Furthermore, there was a borderline significant increase in neuron-glia2-positive cells 8 days after chemotherapy (data not shown).

\section{VE-cadherin-BMDC-derived cells exhibit phenotypic changes as they exit the bone marrow}

Because the EYFP/PECAM ${ }^{\text {low }}$ population exhibited the most significant change in the tumors, we followed this population while in transit to the tumor. FACS analysis revealed that this group of cells made up $2.6 \%$ of the $\mathrm{CD} 45^{-}$population (Figure $4 \mathrm{~A}$ ). Interestingly, in the bone marrow they expressed high levels of PECAM. In the bloodstream, EYFP cells made up $0.47 \%$ of the circulating nucleated cells (Figure 4B). In the tumor, the percentage of these cells ranged from $0.3 \%$ (vehicle treated) to $1.6 \%$ (after chemotherapy treatment) (Figure 4C). Importantly, the level of PECAM was heterogeneous but continued to decrease in the tumors (Figure 4C). We characterized the EYFP population in the 3 different compartments through gene expression profiling. In the bone marrow, we compared the $\mathrm{EYFP}^{-} / \mathrm{PECAM}^{+}$bone marrow cells (Figure 4E) with the EYFP/PECAM ${ }^{+}$bone marrow cells (Figure 4F). As can be observed, the expression profile of several endothelial markers showed a significant level of similarity. This pattern changed as the EYFP population reached the circulation (Figure 4G). In particular, levels of PECAM, VE-cadherin, and VEGFR-2 decreased, while Notch1, Notch ligand $\Delta$-like 4 (Dll4), and Tie2 increased. As the population reached the tumor, a selective increase of MRC-1, a molecule typically expressed by macrophages, was noted (Figure $4 \mathrm{H}$ ).

This analysis revealed that the genetically traced EYFP population changes drastically during its mobilization from the bone marrow, through the circulation, to the tumor (Figure 4D). In general, the endothelial markers (gray) tend to decrease, whereas the macrophage markers (black) tend to increase during this process (Figure 4E-H). Interestingly, Notch1 messenger RNA levels were selectively induced in the subgroup that egressed the bone marrow and gained access to the circulation (Figure 4G). This suggested that Notch signaling might likely participate in the egression of EYFP cells from the bone marrow.

\section{Notch1 in EYFP cells is critical for the egression of these cells from the bone marrow, and its absence enhances response to chemotherapy}

To determine the relevance of Notch signaling in the regulation of chemotherapy-induced egression of the subpopulations of BMDCs, we next used bone marrow from VE-cadherin-Cre-ER ${ }^{\mathrm{T} 2} / \mathrm{NOTCH}^{-/ \mathrm{fl}} /$ EYFP mice and compared these results with the transplantation experiment using the CIVE mice (Figure 5A). These experiments enabled inducible Notch deletion concurrent with EYFP expression upon tamoxifen treatment (supplemental Figure 5). We found similar levels of EYFP cells in the bone marrow (Figure 5B), but significantly lower levels of EYFP cells were circulating in the Notch knockout (KO) mice (Figure 5C) after 8 days of treatment with either the vehicle or cisplatin. Notably, in the CIVE mice at day 1, a (borderline) significant increase was seen after treatment with chemotherapy (supplemental Figure 2); this was not detected in the Notch KO mice (data not shown). Thus, defective Notch signaling does not result in differences in the viability of $\mathrm{EYFP}^{+}$cells within the bone marrow, but Notch is necessary for the egression of EYFP cells from the bone marrow. To exclude that chemotherapy itself influenced Notch signaling in EYFP cells, we performed RT-PCR on Notch, Dll4, and the downstream targets Hes1 and Hey1 in the $\mathrm{EYFP}^{+}$cells with and without chemotherapy. We found no differences in Notch or Dll4 messenger RNA levels after treatment with cisplatin (supplemental Figure 6). In unstimulated EYFP cells, Hes1 or Hey 1 could not be detected; however, after plating the cells on JagFc both genes were induced in a manner that was indistinguishable in each of the groups (vehicle or cisplatin) (supplemental Figure 6).

In the vehicle-treated mice, we found reduced tumor growth in animals with deleted Notch in the bone marrow (Figure 5D). Moreover, the antitumor effect of cisplatin was greatly enhanced when Notch was deleted and tumor growth remained suppressed even 8 days after treatment (Figure 5D). Consistent with the finding that Notch is required for the EYFP cells' egression from the bone marrow, we found only traces of EYFP cells in the tumors of these mice (Figure 5E-F). Furthermore, there was no increase in EYFP cells after chemotherapy (Figure 5E-F). Finally, the number of endothelial cells in the tumor was markedly reduced in mice with Notch-deleted VE-cadherin BMDCs and poor angiogenic activity was noted after chemotherapy (Figure 5E,G). Notably, pericyte coverage in these tumors was at best marginal (supplemental Figure 7). These findings indicate that this small subpopulation of VE-cadherin + BMDCs is responsive to chemotherapy and plays a critical role in stimulating angiogenesis, vessel maturation, and tumor growth.

Finally, we performed an additional experiment in which the deletion of Notch1 was done 2 days after tumor inoculation (Figure 6A). This protocol allowed for egression of BMDCs during the initial days of tumor growth. In these experiments, similar results to those with pretumor deletion of Notch1 were also obtained. Angiogenesis, influx of EYFP cells, and tumor growth were reduced in the mice where the deletion of Notch 1 was induced shortly after tumor transplantation (Figure 6B-D). Overall, the findings indicate that the early egression of EYFP cells was either not sufficient for stimulating angiogenesis or that 
Figure 4. Notch is upregulated in VE-cadherinexpressing cells that egressed the bone marrow. (A-C) FACS sorting results are shown for 3 populations of cells from $(A)$ the bone marrow, $(B)$ the blood, and (C) the tumor of the CIVE mice after tamoxifen induction. (D) Shown is a schematic overview of the different stages of the EYFP ${ }^{+}$cells. (E-H) From the bone marrow, a population of $\mathrm{EYFP}^{-} / \mathrm{PECAM}^{+}$and a population of $\mathrm{EYFP}^{+} / \mathrm{PECAM}^{+}$were sorted. From the blood, the $\mathrm{EYFP}^{+} / \mathrm{PECAM}^{+}$population was sorted RT-PCR was performed for levels of different proteins in the 4 populations: (E) BM EYFP ${ }^{-} / \mathrm{PECAM}^{+}$, (F) BM $\mathrm{EYFP}^{+} / \mathrm{PECAM}^{+}$, (G) blood $\mathrm{EYFP}^{+} / \mathrm{PECAM}^{+}$, and $(\mathrm{H})$ tumor PECAM+/EYFP+, showing the endothelial markers (gray), Notch1/D\|l (red), and the macrophage markers (black). eNOS, endothelial nitric oxide synthase; iNOS, inducible nitric oxide synthase; ICAM, intercellular adhesion molecule; mRNA, messenger RNA; VCAM, vascular cell adhesion molecule.
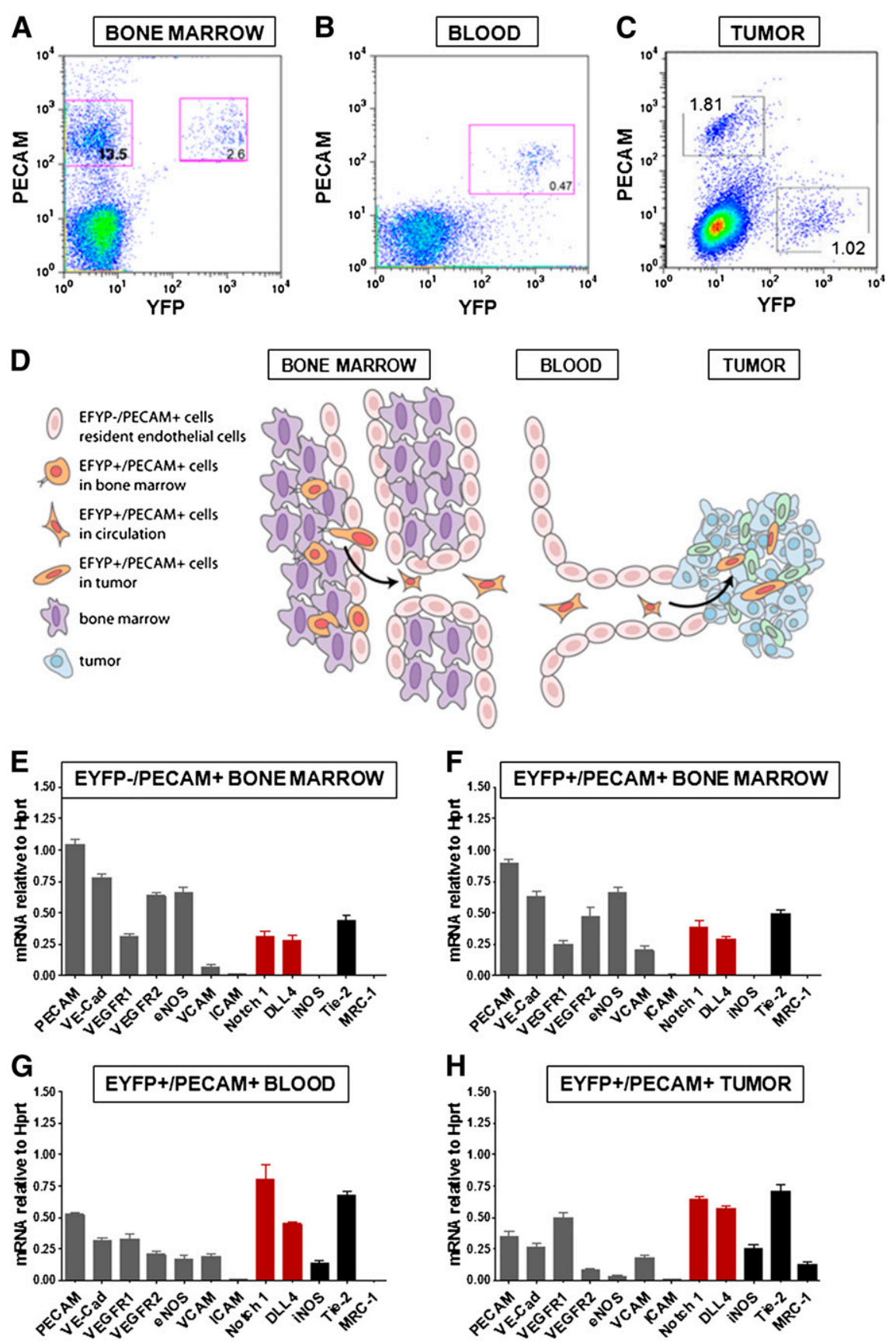

a continuous egression was necessary to support angiogenesis and tumor growth.

\section{Discussion}

A rapidly increasing body of evidence supports the notion that chemotherapy can evoke a host-repair response in which BMDCs are recruited to the tumor. There, BMDCs might facilitate regrowth of the tumor through negating the anticancer effects of chemotherapy. ${ }^{1-9}$ Research specifically identifying relevant subpopulations of chemotherapy-induced BMDCs has been hampered by phenotypic changes as BMDCs migrate from the bone marrow into the circulation and finally into the tumor microenvironment.
Our study used unique mouse models to lineage trace the BMDVE-cadherin-expressing cells into the tumor, thereby bypassing phenotypical changes in this population over time. Using the inducible VE-cadherin/EYFP/Cre model, we focused on the small population $(0.3 \%)$ of adult BMDCs that expressed VE-cadherin in the bone marrow. At least 2 subpopulations could be discriminated. Both were recruited to the tumor microenvironment, and the recruitment was clearly enhanced after chemotherapy, which coincided with an almost twofold increase in endothelial cells and an increased vascular density in the tumor 8 days after chemotherapy. The vast majority of the EYFP cells in the tumor was located perivascularly and did not appear to be incorporated in the vasculature. In fact, although they express VE-cadherin at some point in the bone marrow, these cells are myeloid in nature as per their phenotypic and functional features and are not endothelial cell progenitors. 

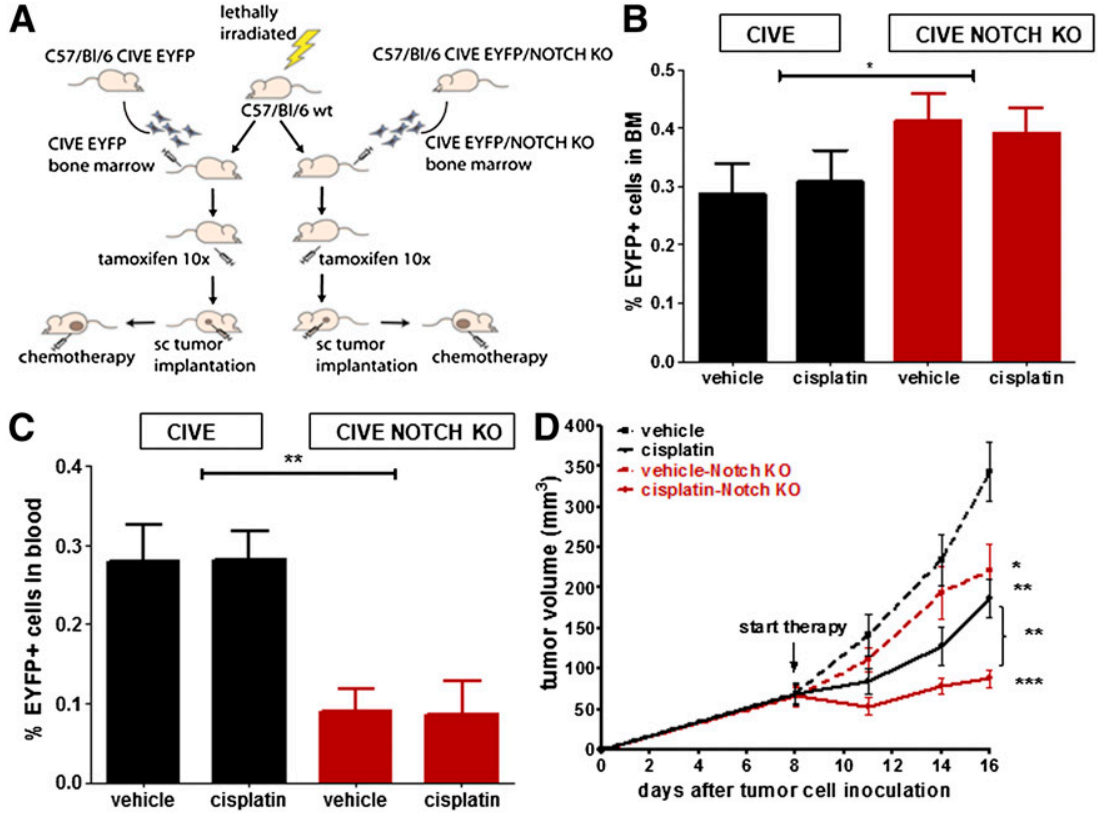

E
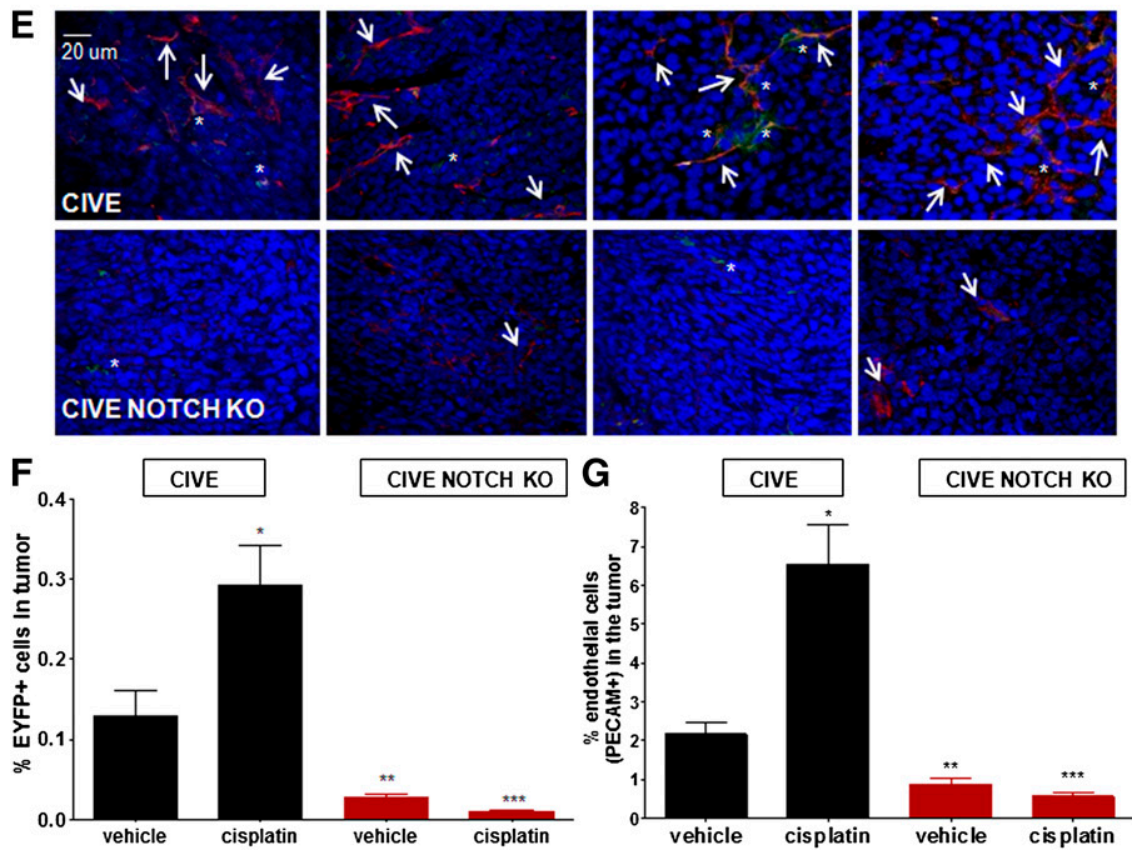

Figure 5. The influx of BMD-VE-cadherin/Notch ${ }^{\text {high }}$ cells confers chemoresistance and enhanced angiogenesis. (A) Shown is a schematic overview of the transplantation model. Tumor growth occurred in LLC cells in C57BL/6 mice transplanted with either CIVE bone marrow or CIVE-Notch KO bone marrow; mice were either untreated or treated with cisplatin. (B-C) The graphs show a comparison of the EYFP ${ }^{+}$cells in (B) the bone marrow (BM) and $(\mathrm{C})$ the blood between the mice transplanted with CIVE or the CIVE-Notch KO bone marrow. (D) The graphs shows a comparison of the tumor growth of LLC cells in C57BL/6 mice transplanted with the CIVE bone marrow vs the CIVE-Notch $\mathrm{KO}$ bone marrow, either untreated or treated with cisplatin. (E) Representative confocal pictures show $\mathrm{EYFP}^{+}$cells in the LLC tumors (blue: DAPI, red: PECAM, green: EYFP) in the mice with the CIVE-Notch $\mathrm{KO}$ bone marrow (upper panels) and the mice with the CIVE bone marrow (lower panels). (F) Shown is the contribution of $\mathrm{EYFP}^{+}$cells to the LLC tumors in $\mathrm{BL} / 6$ mice transplanted with CIVE or CIVE-Notch KO bone marrow 8 days after start treatment. (G) The graph shows the percentage of endothelial cells $\left(\mathrm{PECAM}^{+}\right.$ cells) of the total cells in subcutaneous growing LLC cells in BL/6 mice transplanted with CIVE or CIVENotch KO bone marrow 8 days after the start of treatment. ${ }^{\star} P<.05 ;{ }^{* \star} P<.01 ;{ }^{* \star \star} P<.001$ compared with the CIVE vehicle control. The scale bar applies to all images.
Our findings are in line with other studies showing that a heterogeneous population of BMDCs is found to infiltrate the tumor in response to therapy and interferes with response. We now show that both the $\mathrm{PECAM}^{\mathrm{low}}$ population and the $\mathrm{CD} 11 \mathrm{~b}^{+} / \mathrm{Gr}^{+}$population are in fact derived from the adult VE-cadherin-positive BMDCs, which therefore clearly represent a small but biologically relevant constituency of cells in the bone marrow. Interestingly, once in the tumor, these cells also express high levels of Tie 2 and MRC-1, suggesting a likely overlap with the previously described TAM population. ${ }^{6}$ Previously, vascular disruptive agents, radiotherapy, and chemotherapy were found to recruit both endothelial cell progenitor cells, ${ }^{1-4}$ as hematopoietic cells including Tie2-expressing monocytes, ${ }^{18}$ TAMs, ${ }^{6}$ and $\mathrm{CD} 11 \mathrm{~b}^{+}$myelomonocytic cells. ${ }^{5}$ Importantly, it was shown that targeting both the endothelial as well as the myeloid populations has an additive effect and the influx of CD11b/Gr1-positive cells mediates the refractoriness of tumors to antiangiogenic therapy. ${ }^{7,11,36}$ This suggests shared properties and perhaps redundancy between the different pathways and populations of BDMCs in tumor angiogenesis. It has been further demonstrated that recruitment of BMDCs could be prevented by either targeting the CXC chemokine receptor 4/stromal cell derived factor 1 axis, ${ }^{1,2,4}$ the VEGF pathway, ${ }^{1}$ or the colony stimulating factor 1 receptor. ${ }^{6}$ The present study adds Notch 1 to this panel of therapeutic targets. Mechanistically, we found that Notch1 is critical for the egression of this population from the bone marrow and that this population, albeit small, holds biological significance in both tumor growth and therapeutic response.

It is evident that Notch ligands and receptors play an important role in the differentiation and function of the vasculature. Mice with deficiencies in Notch signaling display severe vascular defects, and haploinsufficiency of Dll4 results in embryonic lethality. ${ }^{37-39}$ Furthermore, Notch signaling in BMD-progenitor cells is important for their proangiogenic effect in both tumor angiogenesis and wound 

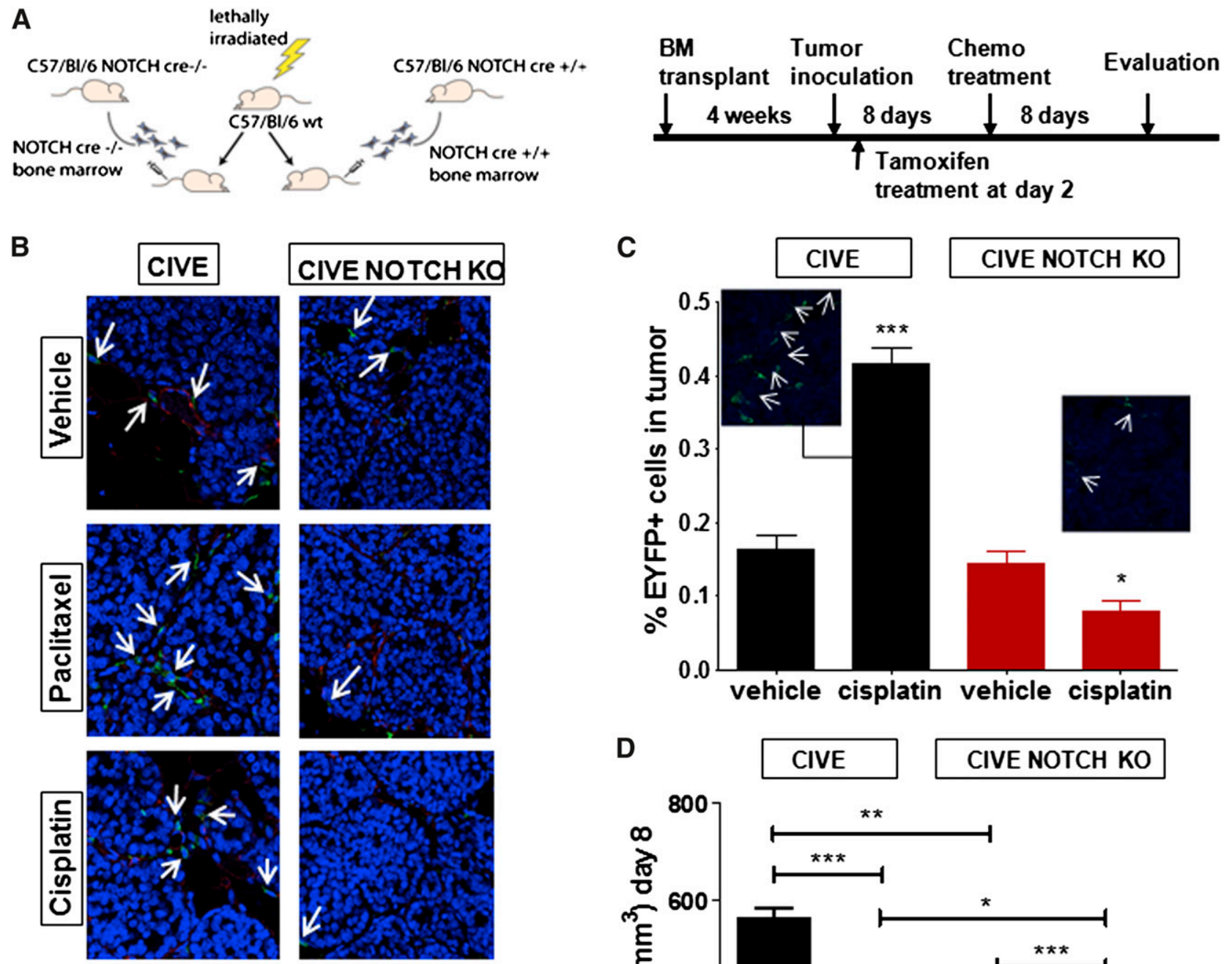

\begin{tabular}{|l|l|l|}
\hline $\begin{array}{l}\text { PECAM+/ } \\
\text { CD45- cells }\end{array}$ & CIVE & NOTCH KO \\
\hline vehicle & $2.0($ SD 0.3) & $1.8($ SD 0.3) \\
\hline cisplatin & $6.2($ SD 1.4) & $3.1($ SD 0.5) \\
\hline
\end{tabular}

C
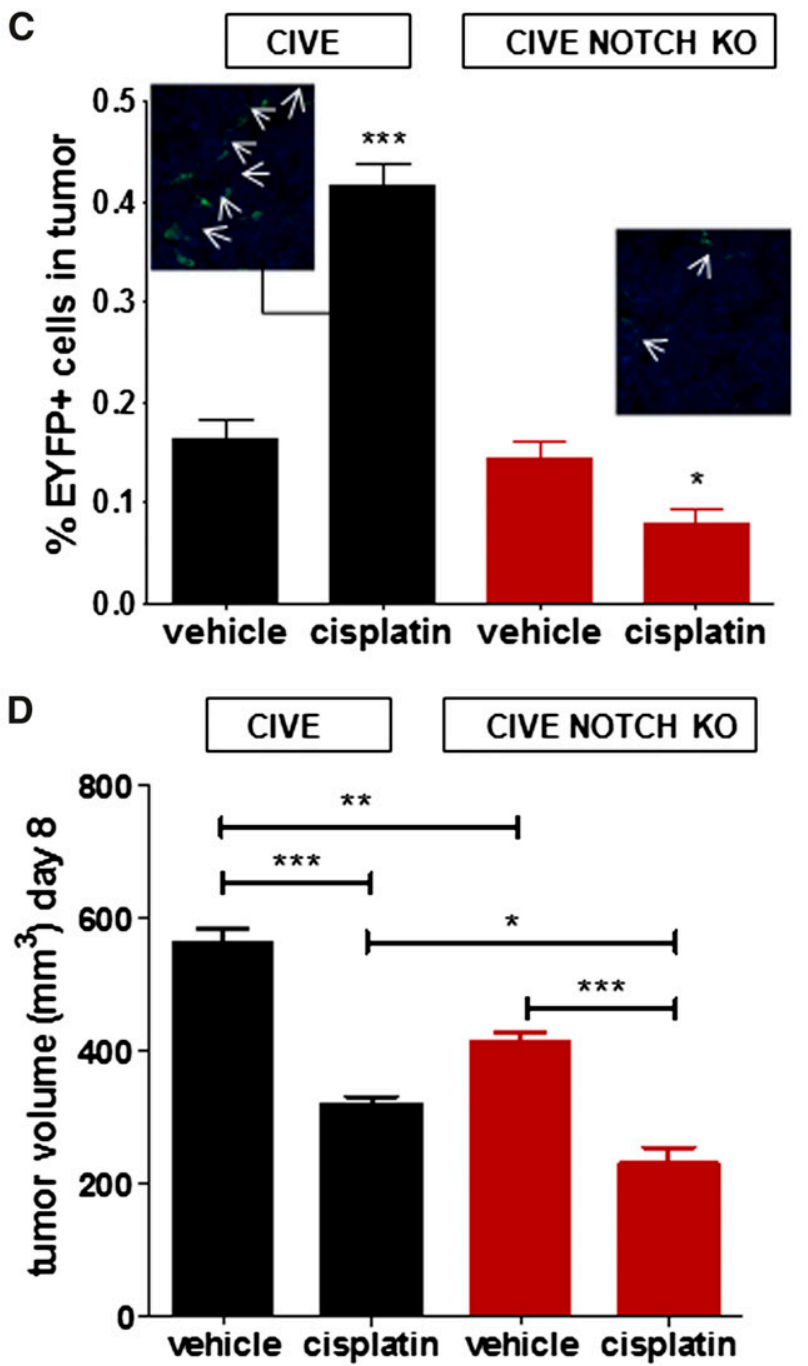

Figure 6. Late deletion of Notch, 2 days after tumor cell inoculation, renders the same effect. (A) The schematic overview shows the transplantation model and experimental procedure. (B) Representative confocal pictures show EYFP ${ }^{+}$cells in the LLC tumors (red: PECAM, green: EYFP) in the mice with the Notch-Cre ${ }^{-l-}$ bone marrow (left panel) and the mice with the Notch-Cre ${ }^{+/+}$bone marrow (right panel) (both treated with the vehicle control, cisplatin, or paclitaxel). In the table (below), mean (standard deviation) $\mathrm{PECAM}^{+} / \mathrm{CD} 45^{-}$cells per treatment group are shown. (C) The graph shows the contribution of EYFP ${ }^{+}$cells to the LLC tumors in BL/6 mice, transplanted, respectively, with the Notch-Cre $^{-/-}$or the Notch-Cre ${ }^{+/+}$bone marrow, shown by FACS analysis and confocal microscopy. (D) The graph shows a comparison of the tumor growth of LLC cells in C57BL/6 mice transplanted with the CIVE bone marrow vs the CIVE-Notch KO bone marrow, either untreated or treated with cisplatin. ${ }^{\star} P<.05 ;{ }^{* \star} P<.01 ;{ }^{\star \star \star} P<.001$. Panel B images were obtained with a $20 \times$ objective.

healing. ${ }^{40,41}$ In contrast, a role of Notch signaling in resistance to chemotherapy is less well established. Notch is a regulator of cancer stem cell programming and contributes to the epithelial-tomesenchymal transition, both associated with anticancer drug resistance. ${ }^{42,43}$ Therefore, targeting Notch could be a novel approach to overcoming the drug resistance of cancer cells by reducing cancer stem cells or epithelial-to-mesenchymal transition processes. Our data revealed an additional Notch-regulated mechanism of chemoresistance through the regulation of angio-supportive BMDC exit from the bone marrow. Strikingly, by specifically preventing the incorporation of these cells into the tumor microenvironment, a significant reduction in angiogenesis and tumor growth was noted. Several Notch inhibitors have been tested for antitumor effects in in vivo models and were shown to be additive to various types of chemotherapy. ${ }^{44,45}$ In addition, Notch inhibition was also found to act synergistically with other antiangiogenic agents. ${ }^{46}$ However, using Notch as a pharmacological target to enhance chemotherapy efficacy has been challenging due to (gastrointestinal) toxicity. ${ }^{47}$

Our findings highlight the importance of specific BMDCs in chemoresistance. Generally, the term "chemoresistance" is used to characterize tumor cell intrinsic mechanisms to neutralize the effects of chemotherapy. However, in the past decade, tumor cell 
extrinsic mechanisms of chemoresistance have been reported. In particular, inflammatory cells and other constituents of the tumor microenvironment all have been shown to render tumors insensitive to chemotherapy as part of a "host response to therapy," even when tumor cells themselves were sensitive to chemotherapy. ${ }^{48}$ Thus, the overall benefit of a treatment is determined by the ratio of the sensitivity of cancer cells to the cytotoxic effects of chemotherapy and the counteracting host responses. In the case of an intrinsic resistant tumor, this could potentially even lead to enhanced tumor growth by having only the tumor promoting effects. ${ }^{49,50}$ Here we show that chemotherapy activates a host response mediated by a specific population of VE-cadherin-expressing BMDCs. This population changes while in transit and acquires some of the features previously associated with TAMs and $\mathrm{CD} 11 \mathrm{~b} / \mathrm{Gr}^{+}$, indicating that these are likely to be the same. In addition, our findings further uncovered the relevance of Notch1 in the egression of these cells and indicate that this might be a potential target to improve chemotherapeutic treatment.

\section{Acknowledgments}

The authors thank Michelle Steel for her technical assistance, the Tissue Procurement Core Laboratory Shared Resource, and the
FACSCalibur Flow Cytometric Facility at the University of California, Los Angeles.

This work was supported by the National Institutes of Health National Cancer Institute (HL085618); California Institute for Regenerative Medicine Award (RB1-01328); and a grant from the Jonsson Cancer Center Foundation.

\section{Authorship}

Contribution: J.M.L.R., H.H., E.E.V., and M.L.I.-A. designed the research; J.M.L.R., H.H., L.G.M.D., A.M., C.L.B., M.v.A., T.F.L, and J.J.H. performed the experiments; F.R. provided the Notch floxed mouse; J.M.L.R., H.H., T.F.L., E.E.V., and M.L.I.-A. analyzed the data; and J.M.L.R., E.E.V., and M.L.I.-A. wrote the paper.

Conflict-of-interest disclosure: The authors declare no competing financial interests.

The current affiliation for A.M. is Institute of Physiology and Cell Biology, National Center for Scientific Research, University of Poitiers, Poitiers, France.

Correspondence: M. Luisa Iruela-Arispe, Department of Molecular, Cell and Developmental Biology, Biomedical Sciences/Orthopaedic Hospital Research Building-Room 447, UCLA, Los Angeles, CA 90095-1570; e-mail: arispe@ mcdb.ucla.edu.

\section{References}

1. Shaked Y, Henke E, Roodhart JM, et al. Rapid chemotherapy-induced acute endothelial progenitor cell mobilization: implications for antiangiogenic drugs as chemosensitizing agents. Cancer Cell. 2008;14(3):263-273.

2. Shaked $\mathrm{Y}$, Ciarrocchi A, Franco M, et al. Therapy-induced acute recruitment of circulating endothelial progenitor cells to tumors. Science. 2006;313(5794):1785-1787.

3. Roodhart JM, Langenberg MH, Vermaat JS, et al. Late release of circulating endothelial cells and endothelial progenitor cells after chemotherapy predicts response and survival in cancer patients. Neoplasia. 2010;12(1):87-94

4. Taylor M, Billiot F, Marty V, et al. Reversing resistance to vascular-disrupting agents by blocking late mobilization of circulating endothelial progenitor cells. Cancer Discov. 2012;2(5): 434-449.

5. Kioi M, Vogel H, Schultz G, Hoffman RM, Harsh GR, Brown JM. Inhibition of vasculogenesis, but not angiogenesis, prevents the recurrence of glioblastoma after irradiation in mice. J Clin Invest. 2010;120(3):694-705.

6. DeNardo DG, Brennan DJ, Rexhepaj E, et al. Leukocyte complexity predicts breast cancer survival and functionally regulates response to chemotherapy. Cancer Discov. 2011;1(1):54-67.

7. Shojaei $F, W u X$, Malik AK, et al. Tumor refractoriness to anti-VEGF treatment is mediated by $\mathrm{CD} 11 \mathrm{~b}+\mathrm{Gr} 1+$ myeloid cells. Nat Biotechnol. 2007;25(8):911-920

8. Roodhart JM, Daenen LG, Stigter EC, et al. Mesenchymal stem cells induce resistance to chemotherapy through the release of platinuminduced fatty acids. Cancer Cell. 2011;20(3): 370-383.

9. Welford AF, Biziato D, Coffelt SB, et al. TIE2expressing macrophages limit the therapeutic efficacy of the vascular-disrupting agent combretastatin A4 phosphate in mice. J Clin Invest. 2011;121(5):1969-1973.
10. Ahn GO, Brown JM. Matrix metalloproteinase- 9 is required for tumor vasculogenesis but not for angiogenesis: role of bone marrow-derived myelomonocytic cells. Cancer Cell. 2008;13(3): 193-205.

11. Lyden D, Hattori K, Dias S, et al. Impaired recruitment of bone-marrow-derived endothelial and hematopoietic precursor cells blocks tumor angiogenesis and growth. Nat Med. 2001;7(11) 1194-1201.

12. De Palma M, Lewis CE. Macrophage regulation of tumor responses to anticancer therapies. Cance Cell. 2013;23(3):277-286

13. Hiratsuka S, Duda DG, Huang Y, et al. C-X-C receptor type 4 promotes metastasis by activating p38 mitogen-activated protein kinase in myeloid differentiation antigen (Gr-1)-positive cells. Proc Natl Acad Sci USA. 2011;108(1):302-307.

14. Dudley AC, Udagawa T, Melero-Martin JM, Shih SC, Curatolo A, Moses MA, Klagsbrun M. Bone marrow is a reservoir for proangiogenic myelomonocytic cells but not endothelial cells in spontaneous tumors. Blood. 2010;116(17): 3367-3371.

15. Coffelt SB, Lewis CE, Naldini L, Brown JM, Ferrara N, De Palma M. Elusive identities and overlapping phenotypes of proangiogenic myeloid cells in tumors. Am J Pathol. 2010;176(4): 1564-1576.

16. Bailey AS, Willenbring $\mathrm{H}$, Jiang $\mathrm{S}$, et al. Myeloid lineage progenitors give rise to vascular endothelium. Proc Natl Acad Sci USA. 2006; 103(35):13156-13161.

17. Fantin A, Vieira JM, Gestri G, et al. Tissue macrophages act as cellular chaperones for vascular anastomosis downstream of VEGFmediated endothelial tip cell induction. Blood. 2010;116(5):829-840.

18. De Palma M, Venneri MA, Galli R, Sergi Sergi L, Politi LS, Sampaolesi M, Naldini L. Tie2 identifies a hematopoietic lineage of proangiogenic monocytes required for tumor vessel formation and a mesenchymal population of pericyte progenitors. Cancer Cell. 2005;8(3):211-226.
19. He H, Xu J, Warren CM, Duan D, Li X, Wu L, Iruela-Arispe ML. Endothelial cells provide an instructive niche for the differentiation and functional polarization of M2-like macrophages. Blood. 2012;120(15):3152-3162.

20. Kaplan RN, Riba RD, Zacharoulis $S$, et al. VEGFR1-positive haematopoietic bone marrow progenitors initiate the pre-metastatic niche. Nature. 2005;438(7069):820-827.

21. Peters BA, Diaz LA, Polyak K, et al. Contribution of bone marrow-derived endothelial cells to human tumor vasculature. Nat Med. 2005;11(3): 261-262.

22. Ruzinova MB, Schoer RA, Gerald W, et al. Effect of angiogenesis inhibition by Id loss and the contribution of bone-marrow-derived endothelial cells in spontaneous murine tumors. Cancer Cell. 2003;4(4):277-289.

23. Duda DG, Cohen KS, Kozin SV, Perentes JY, Fukumura D, Scadden DT, Jain RK. Evidence for incorporation of bone marrow-derived endothelial cells into perfused blood vessels in tumors. Blood. 2006;107(7):2774-2776.

24. Bertolini F, Shaked Y, Mancuso P, Kerbel RS The multifaceted circulating endothelial cell in cancer: towards marker and target identification. Nat Rev Cancer. 2006;6(11):835-845.

25. Yoder MC, Mead LE, Prater D, et al. Redefining endothelial progenitor cells via clonal analysis and hematopoietic stem/progenitor cell principals. Blood. 2007;109(5):1801-1809.

26. Srinivas $\mathrm{S}$, Watanabe $\mathrm{T}$, Lin CS, William CM, Tanabe $Y$, Jessell TM, Costantini F. Cre reporter strains produced by targeted insertion of EYFP and ECFP into the ROSA26 locus. BMC Dev Biol. 2001;1:4.

27. Soriano P. Generalized lacZ expression with the ROSA26 Cre reporter strain. Nat Genet. 1999; 21(1):70-71.

28. Zovein AC, Hofmann JJ, Lynch M, et al. Fate tracing reveals the endothelial origin of hematopoietic stem cells. Cell Stem Cell. 2008; 3(6):625-636. 
29. Alva JA, Zovein AC, Monvoisin A, et al. VECadherin-Cre-recombinase transgenic mouse: a tool for lineage analysis and gene deletion in endothelial cells. Dev Dyn. 2006;235(3):759-767.

30. Monvoisin A, Alva JA, Hofmann JJ, Zovein AC, Lane TF, Iruela-Arispe ML. VE-cadherinCreERT2 transgenic mouse: a model for inducible recombination in the endothelium. Dev Dyn. 2006; 235(12):3413-3422.

31. Radtke F, Wilson A, Stark G, Bauer M, van Meerwijk J, MacDonald HR, Aguet M. Deficient $T$ cell fate specification in mice with an induced inactivation of Notch1. Immunity. 1999;10(5): 547-558.

32. Gao D, Nolan DJ, Mellick AS, Bambino K, McDonnell K, Mittal V. Endothelial progenitor cells control the angiogenic switch in mouse lung metastasis. Science. 2008;319(5860):195-198.

33. Nolan DJ, Ciarrocchi A, Mellick AS, et al. Bone marrow-derived endothelial progenitor cells are a major determinant of nascent tumor neovascularization. Genes Dev. 2007;21(12): 1546-1558.

34. Jain RK, Duda DG. Role of bone marrow-derived cells in tumor angiogenesis and treatment. Cancer Cell. 2003;3(6):515-516.

35. Chan DA, Kawahara TL, Sutphin PD, Chang HY, Chi JT, Giaccia AJ. Tumor vasculature is regulated by PHD2-mediated angiogenesis and bone marrow-derived cell recruitment. Cancer Cell. 2009;15(6):527-538.
36. Shojaei F, Ferrara N. Refractoriness to antivascular endothelial growth factor treatment: role of myeloid cells. Cancer Res. 2008;68(14): 5501-5504.

37. Krebs LT, Xue Y, Norton CR, et al. Notch signaling is essential for vascular morphogenesis in mice. Genes Dev. 2000;14(11):1343-1352.

38. Hofmann JJ, Iruela-Arispe ML. Notch signaling in blood vessels: who is talking to whom about what? Circ Res. 2007;100(11):1556-1568.

39. Gale NW, Dominguez MG, Noguera I, et al. Haploinsufficiency of delta-like 4 ligand results in embryonic lethality due to major defects in arteria and vascular development. Proc Natl Acad Sci USA. 2004;101(45):15949-15954.

40. Caiado F, Real C, Carvalho T, Dias S. Notch pathway modulation on bone marrow-derived vascular precursor cells regulates their angiogenic and wound healing potential. PLOS ONE. 2008;3(11):e3752.

41. Real C, Remédio L, Caiado F, et al. Bone marrowderived endothelial progenitors expressing Deltalike 4 (DII4) regulate tumor angiogenesis. PLOS ONE. 2011;6(4):e18323.

42. Wang Z, Li Y, Ahmad A, Azmi AS, Banerjee S, Kong D, Sarkar FH. Targeting Notch signaling pathway to overcome drug resistance for cancer therapy. Biochim Biophys Acta. 2010;1806(2): 258-267.

43. Wang Z, Li Y, Kong D, et al. Acquisition of epithelial-mesenchymal transition phenotype of gemcitabine-resistant pancreatic cancer cells is linked with activation of the notch signaling pathway. Cancer Res. 2009;69(6):2400-2407.

44. Meng RD, Shelton CC, Li YM, Qin LX, Notterman D, Paty PB, Schwartz GK. gamma-Secretase inhibitors abrogate oxaliplatin-induced activation of the Notch-1 signaling pathway in colon cance cells resulting in enhanced chemosensitivity. Cancer Res. 2009;69(2):573-582.

45. Gu F, Ma Y, Zhang Z, Zhao J, Kobayashi H, Zhang L, Fu L. Expression of Stat3 and Notch1 is associated with cisplatin resistance in head and neck squamous cell carcinoma. Oncol Rep. 2010; 23(3):671-676.

46. Li JL, Sainson RC, Oon CE, et al. DLL4-Notch signaling mediates tumor resistance to anti-VEGF therapy in vivo. Cancer Res. 2011;71(18): 6073-6083.

47. Shih IM, Wang TL. Notch signaling, gammasecretase inhibitors, and cancer therapy. Cancer Res. 2007;67(5):1879-1882.

48. Kerbel RS, Ebos JM. Peering into the aftermath The inhospitable host? Nat Med. 2010;16(10): 1084-1085.

49. El Sharouni SY, Kal HB, Battermann JJ. Accelerated regrowth of non-small-cell lung tumours after induction chemotherapy. $\mathrm{Br} \mathrm{J}$ Cancer. 2003;89(12):2184-2189.

50. Bourhis J, Wilson G, Wibault $P$, et al. Rapid tumor cell proliferation after induction chemotherapy in oropharyngeal cancer. Laryngoscope. 1994; 104(4):468-472. 